\title{
O CONCEITO DE SEGURANÇA NACIONAL NA DOUTRINA JURÍDICA BRASILEIRA (1935-48)
}

Ivan Albuquerque Araujo ${ }^{1}$

\section{RESUMO}

Este artigo pretende estudar as disputas lexicais em torno do conceito de Segurança Nacional, recuperando a agência das lógicas "vencedoras" e das lógicas “derrotadas" e mapeando as forças políticas e sociais que influenciaram os juristas e que, por ventura, "condicionaram" a discussão sobre a Segurança Nacional no Brasil. O recorte cronológico utilizado inicia-se com as discussões, no âmbito da Câmara dos Deputados, em torno da Lei de Segurança Nacional (Lei n 38/1935) e termina com a influência americana, através da National War College, a partir de 1949. Utilizando como fonte os escritos e decisões proferidas pelo jurista-político, João Mangabeira; pelo Ministro do STF, Carlos Maximiliano; e pelo especialista em Direito Penal, Nelson Hungria. Atentando mais para o processo de discussão e aplicação da lei, do que para seu conteúdo stricto sensu. A partir disso, foi possível observar a proximidade entre segurança nacional e a fabricação de um tipo social desprovido de direitos.

Palavras-chave: Segurança Nacional; história dos conceitos; autoritarismo.

\section{THE CONCEPT OF NATIONAL SECURITY IN THE BRAZILIAN LEGAL DOCTRINE (1935-48)}

\section{ABSTRACT}

This article intends to study the lexical disputes around the concept of National Security, recovering the agency from the "winning" logics and the "defeated" logics and mapping the political and social forces that influenced the jurists and that, by chance, "conditioned" the discussion about National Security in Brazil. The chronological cut used begins with the discussions, within the Chamber of Deputies, around the National Security Law (Nº 38/1935) and ends with American influence, through the National War College, from 1949. Using as a source the writings and decisions pronounced by the political graduate in law, João Mangabeira; by the Minister of the STF, Carlos Maximiliano; and in the academic, Nelson Hungria. Focusing more on the process of discussion and law enforcement than on its stricto sensu content. From this, it was possible to observe the proximity between national security and the fabrication of a social type deprived of rights.

\footnotetext{
${ }^{1}$ Mestrando em Ciências Sociais no PPGCIS/PUC-Rio; Bolsista de Mestrado da CAPES/CNPQ; zeix100@gmail.com

CSOnline - Revista Eletrônica de Ciências Sociais, Juiz de Fora, n. 25 (2017), pp. 1-296.
} 
Keywords: National Security; conceptual history; authoritarianism.

\section{INTRODUÇÃO}

O tema do presente artigo são as disputas políticas e sociais em torno do conceito jurídico $^{2}$ de "Segurança Nacional" e de expressões correlatas, identificando como estas disputas influenciaram na estrutura social. Este conceito é extremamente polissêmico e nas discussões jurídicas do período (1935-1948) aparece sob outras formas, como: salvação pública; ordem política e social; segurança do Estado; e segurança das instituições. (GASPARI, 2014, p. 10-11).

O principal objetivo de um trabalho que visa estudar "disputas lexicais" no passado é a de conseguir recuperar a agência de lógicas teóricas derrotadas. Exatamente porque, a lógica vitoriosa assumiu essa posição por escolha do poder político e não, necessariamente, pela força argumentativa. (JASMIN, 2015). Disso decorre a importância de estudar juristas que se mostraram a favor do recrudescimento das práticas repressivas do Estado, bem como, os que fizeram oposição ao avanço da agenda pró-segurança nacional $^{3}$.

Dada a extensa variação de termos na contenda jurídica sobre Segurança Nacional, argumento que cada um deles revela informações importantes sobre o enunciador e sua forma de racionalizar a "batalha semântica". Por exemplo, o termo que cada ator social utiliza revela as impressões pessoais e as do grupo que está inserido sobre a funcionalidade política da expressão usada.

Para a análise das fontes tomaremos alguns cuidados, os dois de natureza metodológica. O primeiro diz respeito a não atribuir uma correlação imediata entre a mudança das ideias políticas e os eventos ocorridos; isto porque, mudanças de conjuntura não implicam necessariamente uma mudança no vocábulo utilizado; e a lógica oposta também é válida, isto é, mudanças no conceito não indicam necessariamente mudanças conjunturais ${ }^{4}$.

O segundo refere-se à circunscrição do tema de pesquisa a um escopo bem delimitado tanto no que corresponde aos juristas estudados (Carlos Maximiliano, João Mangabeira e Nelson Hungria) quanto no que diz respeito ao recorte cronológico (1935-

\footnotetext{
${ }^{2}$ Esta discussão jurídica insere-se no campo do Direito Penal.

${ }^{3}$ Argumento que a legislação de Segurança Nacional caminhou em direção a dificultar cada vez mais o direito de defesa, o que pode ser percebido pela análise das Leis n³8/1935 e 136/1935 e dos DecretosLei $n^{\circ} 431 / 1938$ e $n^{\circ} 4766 / 1942$.

${ }^{4}$ Este primeiro cuidado metodológico é fruto das recomendações metodológicas feitas por MESURINI et al (2012, p. 10-2), no estudo da doutrina de Segurança Nacional durante a Ditadura Militar.

CSOnline - Revista Eletrônica de Ciências Sociais, Juiz de Fora, n. 25 (2017), pp. 1-296.
} 
48). Faz-se necessário, portanto, explicar nos próximos parágrafos as razões para tais delimitações na temática de pesquisa.

O objeto do trabalho concentra-se na discussão conceitual de Segurança Nacional, durante os anos de 1935-48, circunscrita aos escritos e decisões proferidas pelo juristapolítico ${ }^{5}$, João Mangabeira; pelo Ministro do $\mathrm{STF}^{6}$, Carlos Maximiliano; e pelo especialista em Direito Penal, Nelson Hungria.

João Mangabeira ${ }^{7}$, filho de farmacêutico, formou-se em Ciências Jurídicas pela faculdade de direito de Salvador em 1987 e fez carreira como advogado na cidade de Ilhéus, por conta da atividade profissional criou vínculos com boa parte da elite baiana. Exerceu diversos cargos políticos como deputado federal pela Bahia por oito legislaturas (entre 1909 e 1950), ministro de Minas e Energia e ministro da Justiça na década de 1960. Notabilizou-se pela crítica a retroatividade penal e por fundar, junto com o Deputado Abel Chermont, o "grupo parlamentar pró-liberdades"8, este grupo tinha por objetivo lutar pelas garantias constitucionais e frear o avanço do movimento integralista.

Carlos Maximiliano ${ }^{9}$ foi deputado federal por Rio Grande do Sul em duas oportunidades, nomeado Consultor-Geral da República em 1932, Procurador-Geral da República em 1934 e ministro do STF em 1936, possui grande importância pelo seu entendimento dos limites do Habeas Corpus. Em sua atuação como ministro do STF, Carlos Maximiliano destacou-se no plano do direito tributário e direito penal. (GODOY, 2010, p. 17-8).

Nelson Hungria ${ }^{10}$ foi desembargador e delegado de polícia, ambos no Distrito Federal; além de ministro do STF, entre 1951-61; foi um dos autores do anteprojeto do

\footnotetext{
${ }^{5}$ Ver VIANNA, 1986.

${ }^{6}$ A Constituição Federal de 1934 atribuía, ao órgão de cúpula do poder judiciário, o nome de "Corte Suprema"; enquanto a Constituição de 1937 utilizava o nome de "Supremo Tribunal Federal". Para evitar confusão no leitor, utilizarei "Supremo Tribunal Federal (STF)" em ambos os casos.

${ }^{7}$ Informações Biográficas retiradas de: MOREIRA. Regina da Luz. MANGABEIRA, João. Dicionário HistóricoBiográfico Brasileiro. Disponível em: http://cpdoc.fgv.br/acervo/dhbb. Acesso em: 31 out. 2016.

${ }^{8} \mathrm{O}$ grupo parlamentar pró-liberdades populares foi um "Bloco parlamentar, também chamado de Frente Parlamentar Pró-Liberdades Populares, constituído em 11 de novembro de 1935 para defender as liberdades constitucionais e combater o movimento integralista. Esvaziou-se a partir de março de 1936, quando alguns de seus mais importantes integrantes foram presos. Diante da intensificação da repressão governamental após o fechamento da Aliança Nacional Libertadora (ANL) em julho de 1935, alguns parlamentares decidiram formar o Grupo Parlamentar Pró-Liberdades Populares." Para mais informações: LAMARÃO, Sérgio. GRUPO PARLAMENTAR PRÓ-LIBERDADES POPULARES. Dicionário Histórico-Biográfico Brasileiro. Disponível em: http://cpdoc.fgv.br/acervo/dhbb. Acesso em: 31 out. 2016.

${ }^{9}$ Informações Biográficas retiradas de: MOREIRA. Regina da Luz. MAXIMILIANO, Carlos. Dicionário Histórico-Biográfico Brasileiro. Disponível em: http://cpdoc.fgv.br/acervo/dhbb. Acesso em: 29 out. 2016.

${ }^{10}$ Informações Biográficas retiradas de: LEMOS, Renato. HUNGRIA, Nelson. Dicionário HistóricoBiográfico Brasileiro. Disponível em: http://cpdoc.fgv.br/acervo/dhbb. Acesso em: 15 jun. 2016. CSOnline - Revista Eletrônica de Ciências Sociais, Juiz de Fora, n. 25 (2017), pp. 1-296.
} 
Código Penal de $1940^{11}$ e um importante comentador sobre o Direito Penal brasileiro ${ }^{12}$. Sua pertinência na discussão sobre o conceito jurídico de "Segurança Nacional", é observável pela crítica constante a Escola de Kiel ${ }^{13}$. A relevância de estudar a jurisprudência do magistrado Nelson Hungria consiste em um aparente paradoxo em sua atuação. Ao passo que argumenta que a fundamentação jurídica da Escola é uma ficção, servindo apenas para os propósitos autoritários dos regimes fascistas, como já mencionamos, mostra-se contrário à concessão de Habeas Corpus a réus condenados pelo Tribunal de Segurança Nacional, mostrando em alguns casos, uma argumentação consoante com a Escola que outrora atacava. (HUNGRIA, 1943).

No que tange às fontes para operacionalizar a análise do meu objeto de pesquisa, serão utilizados os livros "Memória jurisprudencial: Ministro Nelson Hungria" (FUCK, 2012) e "Memória jurisprudencial: Ministro Carlos Maximiliano" (GODOY, 2010); estes, fazem parte de uma coleção do Supremo Tribunal Federal que tem por objetivo mapear a jurisprudência dos Ministros, ou seja, o conjunto de interpretações de leis do magistrado ao longo do tempo. Outra fonte que será de suma importância para a realização da pesquisa é o artigo de Hungria, intitulado A Evolução do Direito Penal Brasileiro. Nele, Hungria, tece duras críticas à Escola de Kiel e ao conceito de Segurança Nacional.

As fontes referentes a João Mangabeira diferem-se das fontes dos demais juristas por um motivo simples. Enquanto, os outros dois foram magistrados federais de carreira e acumularam uma jurisprudência durante a vida, Mangabeira foi um Jurista-político, e sua contraposição à doutrina de segurança nacional ocorreu de forma mais difusa. Para dar conta das manifestações do Deputado João Mangabeira, utilizarei os discursos e manifestações do parlamentar (MOURELLE, 2015 e SILVA NETO, 2006) e um artigo sobre suas concepções constitucionalistas ${ }^{14}$.

\footnotetext{
${ }^{11}$ Decreto-lei n.o 2.848, de 7 de dezembro de 1940

${ }^{12}$ Para mais informações sobre os comentários sobre o Código Penal de 1940: Ver Hungria, 1943.

${ }^{13}$ A Escola de Kiel foi criada durante a década de 1930 como suporte jurídico ao Direito Penal do Terceiro Reich. A doutrina do direito penal da escola "afirmava que a teoria do bem jurídico era consequência do liberalismo do século XIX, incabível num Estado autoritário, em que o crime é essencialmente violação de um dever de obediência ao Estado. Tratava-se de um processo de subjetivação do direito penal, no qual se atribuía à vontade a primazia na elaboração doutrinária, de sorte que o bem jurídico aparecia como um aspecto materialista, absolutamente secundário." (FRAGOSO, 1977, pág. 7). Esta escola de Direito Penal caracteriza-se pela instrumentalização do direito em favor de práticas repressivas do Estado, tratase de um direito em que as liberdades individuais podem ser infringidas em prol dos "interesses do Estado". Para informações sobre as críticas de Nelson Hungria a Escola de Kiel, ver DAL RI Jr, 2013; FRAGOSO, 1977, p. 7-10.

${ }^{14}$ REVISTA DE INFORMAÇÃO LEGISLATIVA: v. 17, n. 66. p. 27-44 (abr./jun. 1980).

CSOnline - Revista Eletrônica de Ciências Sociais, Juiz de Fora, n. 25 (2017), pp. 1-296.
} 
O recorte cronológico (1935-48) definido não é, de forma alguma, aleatório. Inicia-se com as discussões, no âmbito da Câmara dos Deputados, da lei que viria a ser conhecida como Lei de Segurança Nacional (Lei n 38/1935), encerrando em 1948; por ser o ano em que o Marechal César Obino visitou a National War College ${ }^{15}$; e aprendera os preceitos que fundariam a Escola Superior de Guerra $(\mathrm{ESG})^{16}$; defendo aqui que estes novos valores aprendidos na "Escola de Guerra americana" criam uma ruptura no conceito de Segurança Nacional, que justificariam o recorte cronológico. No período compreendido por estes dois marcos, podemos observar um processo contínuo de cerceamento do direito de defesa ${ }^{17}$.

Este artigo é dividido em quatro seções, na primeira seção, explicarei a metodologia utilizada para estudar o conceito de Segurança Nacional, mostrando as duas "escolas" que têm por objeto a história das ideias: tanto o Contextualismo Linguístico quanto a História dos $\operatorname{Conceitos}^{18}$. Na segunda seção, discutirei a bibliografia que trata do conceito de segurança nacional na doutrina brasileira, abarcando também, alguns trabalhos sobre o Tribunal de Segurança Nacional, órgão que, ao mesmo tempo, utilizou de determinada significação do que é a "segurança nacional", mas ajudou a criar mecanismos que "legitimassem" ações futuras em nome da "segurança nacional". No final desta seção, apresentarei os eixos sob os quais centraremos a análise da produção dos juristas. Na terceira sessão, farei a análise dos escritos dos juristas escolhidos; utilizando a metodologia e os eixos apresentados na segunda seção. Na última seção, será realizado um balanço com os resultados encontrados e reflexões para trabalhos futuros.

\section{METODOLOGIA}

O suporte teórico do trabalho é a História dos Conceitos, elaborada pelo historiador alemão Reinhart Koselleck. Faz-se necessário explicar nessa seção: a) qual a importância de estudar a linguagem na pesquisa historiográfica; b) porque escolher a abordagem da História dos Conceitos em detrimento ao Contextualismo Linguístico, de Quentin Skinner.

Jasmin (2015) nos ajuda a explicar o primeiro passo da escolha teórica. Sua argumentação nos chama atenção para o potencial hermenêutico da linguagem em relação ao contexto histórico que o cerca. Os significados linguísticos, dessa forma, limitam,

\footnotetext{
${ }^{15}$ A escola de defesa Americana. Ver o endereço eletrônico <http://nwc.ndu.edu/>

${ }^{16}$ Endereço eletrônico <http://www.esg.br/index.php/br/2014-02-19-17-51-50/nossa-historia>

${ }^{17}$ Como afirmam AVELAR et al,2010; CAMPOS, 1982.

18 Para informações sobre o Contextualismo Linguístico ver SKINNER, 1999. Sobre a História dos Conceitos ver KOSELLECK, 1999, 2006.

CSOnline - Revista Eletrônica de Ciências Sociais, Juiz de Fora, n. 25 (2017), pp. 1-296.
} 
enquadram e criam as possibilidades de experiência e compreensão da realidade social. Ou seja, não poderíamos fazer uma pesquisa de "história social" sem contarmos com uma reflexão sobre o (s) significado (s) dos termos dentro da concepção dos próprios contemporâneos da época estudada. No que tange ao diagnóstico, Skinner e Koselleck têm muito em comum: denunciam os problemas em utilizar conceitos "atemporais" e de, sobretudo, "fazer história" baseando-se em concepções atuais, retirando dos atores sociais a racionalidade que possuíam.

Entretanto, no que se refere ao prognóstico, estes autores possuem suas divergências; o que nos força a escolher uma forma de estudar a linguagem em perspectiva histórica. Para Skinner, o fundamental é entender porque determinado recurso linguístico têm efeito; ou seja, está preocupado em entender a eficácia da ideia abstrata no jogo de "performances" dos atores sociais (Idem, p.28). O significado da palavra em si, importa menos do que o significado da enunciação como um "ato de fala"(Idem, p. 31). Como afirma Skinner, em sua análise, o contexto de produção é indissociável das ideias políticas. É o contexto que dá a “força” da proposição. (SKINNER, 1999).

Enquanto Skinner preocupa-se com o contexto e com os atos de fala, a preocupação central de Koselleck é a mudança conceitual ao longo do tempo; a relação intrínseca entre linguagem e história (KOSELLECK, 2006). Para ele, “[...] um conceito [...] para poder ser um conceito, deve manter-se polissêmico. Embora o conceito também esteja associado à palavra, ele é mais do que uma palavra: uma palavra se torna um conceito se a totalidade das circunstâncias político-sociais e empíricas, nas quais e para as quais essa palavra é usada, se agrega a ela.” (Idem, p. 109).

Ou seja, a "batalha semântica" é intensificada em momentos de crise e ruptura institucional, exatamente pelas várias correntes que buscam atribuir a um conceito a sua visão. Então, grande quantidade de situações práticas são indissociáveis da palavra que usamos para descrevê-la. E é essa capacidade de ser sensível a múltiplos significados dentro de só um conceito tornam a abordagem da História dos Conceitos mais apropriada para o trabalho.

Com o enquadramento teórico realizado, debruço-me, agora, na explicação da metodologia que será empregada no tratamento das fontes. No plano teórico a metodologia criada por Koselleck faz todo o sentido. Mas, resta um esforço de aproximar este método de pesquisa com a aplicação prática nas fontes disponíveis, ou seja, como operacionalizar a análise. 
Como foi possível observar na seção anterior, a História dos Conceitos pretendese uma abordagem reflexiva sobre o pensamento político e social, identificando seus processos de continuidade e ruptura entre história e linguagem. O exercício de análise das fontes seria, então, um esforço de recuperar interpretações jurídicas do passado, conferindo-lhe a racionalidade que possuíam, atentando para utilizar os termos que consigam transmitir o significado lexical da época. Koselleck em Crítica e Crise nos permite observar que não se trata de estudarmos separadamente o contexto político de um lado e o das ideias de outro, mas sim de examinar a função política que o pensamento e as aspirações da burguesia tiveram no âmbito do Estado absolutista, isto é, como determinados conceitos justificam/proporcionam certos movimentos, mudanças políticas. No caso desta pesquisa, entender a função política de determinada concepção jurídica para "legitimar" o instrumento persecutório do Estado.

Por fim, a abordagem defendida por Koselleck propõe alguns cuidados na análise historiográfica de um conceito (KOSSELECK, 2006). O primeiro cuidado, diz respeito, ao apontamento da "linguagem específica" do período, ou seja, um exercício diacrônico de "traduzir significados lexicais em uso no passado para a nossa compreensão atual." (Idem, p. 104); um segundo cuidado consiste em se ater às "situações específicas", isto é, um ponto de vista polêmico, a polissemia natural de um conceito, aponta para uma concepção de futuro, uma perspectiva de ação; seguindo, temos o terceiro cuidado, que nada mais é do que a forma pela qual os conceitos são elaborados e usados; devemos nos atentar à função e à performance dos conceitos (a hermenêutica), mas não apenas aos aspectos linguísticos mas, também aos aspectos "pré-linguísticos" (concepções compartilhadas no período: certo/errado, dentro/fora) e os extralinguísticos (estes sim, contextuais); e o quarto, e último, trata de relacionar o uso do conceito com os grupos que o sustentam e que o contestam.

\section{DISCUSSÃO BIBLIOGRÁFICA}

Os estudos sobre Segurança Nacional no Brasil possuem duas características fundamentais. A primeira diz respeito ao fato de que grande parte dos estudos acadêmicos sobre o conceito de Segurança Nacional no Brasil remonta ao pós-guerra, justamente para explicar a Doutrina de Segurança Nacional na Ditadura Civil-Militar de 1964. Ou seja, os estudos no Brasil sobre segurança Nacional têm como marco inicial a criação da ESG em 1949.

Maria Celina D'Araujo (2006) afirma que “a literatura brasileira trata a segurança nacional como um fenômeno típico da guerra fria" (Idem, p. 1) e não como o CSOnline - Revista Eletrônica de Ciências Sociais, Juiz de Fora, n. 25 (2017), pp. 1-296. 
desenvolvimento de uma política de Estado, durante todo o século XX. A Segurança Nacional deveria ser entendida, segundo a autora, levando em consideração dois aspectos fundamentais: a) o conceito de Segurança Nacional teve seu desenvolvimento atrelado a um projeto militar, mas, não se resume a ele; e b) a questão da segurança nacional foi tratada no país de forma autoritária. (Idem, p. 2-3).

Ou seja, devido à escassez de estudos que abordem o processo de disputa lexical no que tange à discussão do conceito de Segurança Nacional no período anterior a 1948; este trabalho assume um papel de minimizador das lacunas deixadas pela historiografia pregressa $^{19}$, ainda que não busque dar conta de todas as lacunas. Reafirmando, portanto, a importância deste.

A segunda característica versa sobre o foco em aspectos legais e doutrinários que a maioria esmagadora dos trabalhos sobre Segurança Nacional no Estado Novo possuem. Estes estudos, muitas vezes, explicam através de aspectos discricionários a tese de que o Estado Novo buscou progressivamente uma maior eficiência na punição de seus opositores $^{20}$. Como Dal Ri Jr (2013) que possui uma preocupação doutrinária, centrando a análise na mudança que a Lei de Segurança Nacional (LSN) de 1935 criava no ordenamento jurídico brasileiro. Segundo ele, a mudança causada pela implementação da LSN fez com que, por um lado, o código penal não fosse "manchado" pela política e, por outro, que a legislação especial da segurança nacional fosse baseada "em uma norma externa ao código." (Idem, p. 7-8).

É importante frisar que o ineditismo deste estudo está presente, também, por afastar-se da discussão puramente legal; buscando dar conta das disputas semânticas sobre a Segurança Nacional e como estas disputas "legitimam" determinada atuação por parte do Estado.

Para além das duas características da bibliografia que foram citadas. Existem, também, os trabalhos que de alguma forma buscam conceituar a expressão segurança nacional no período histórico trabalhado. Comblin (1978) sintetiza o que é a Doutrina no pós-64. Para ele, a doutrina perpassa as fronteiras nacionais, existindo elementos comuns entre os diversos países latino-americanos (Idem, p. 13). Ao fim de sua análise diz que um dos elementos que ajuda a explicar a doutrina de segurança nacional do pós-64 é o apelo à "ordem político e social” no governo Vargas, isto é, a literatura sobre a doutrina

\footnotetext{
${ }^{19}$ Sobre o conceito de Segurança Nacional no período da Ditadura de 1964: ver COMBLIN, 1978; DAL RI Jr, 2013; D'ARAUJO, 2010.

20 Sobre estudos que mostram como a Legislação de Segurança Nacional utilizou diversos aspectos discricionários para tornar a repressão mais eficaz ver AVELAR et al, 2010; BALZ, 2009 e CAMPOS, 1982. CSOnline - Revista Eletrônica de Ciências Sociais, Juiz de Fora, n. 25 (2017), pp. 1-296.
} 
de segurança nacional do pós-64 reafirma a importância de entendermos determinada lógica gestada durante o governo Varguista (Idem, p. 152).

Maria Celina D’Araujo (2006), segue outra linha, argumenta que existe uma continuidade mais clara entre o conceito entre o período anterior e posterior a 1948. Para ela, as expressões correlatas da Segurança Nacional dizem respeito, na década de 1930, a um conjunto de significados que extrapola a simples noção de "Segurança do Estado"21. Tanto a segurança de uma forma específica de organização estatal quanto a segurança do grupo que ocupava os principais cargos do Estado.

\section{Militância parlamentar: o estudo do caso de João Mangabeira}

Antes de iniciar a análise das peças jurídicas sobre o conceito de Segurança Nacional per se, acredito que é necessário mostrar como parte da imprensa aborda a discussão e como os primeiros contornos referentes à segurança nacional foram delineados por alguns jornais. Parte do pressuposto de que as discussões no parlamento brasileiro, em jornais, o discurso oficial do Estado, e até mesmo as discussões doutrinárias sobre o conceito de Segurança Nacional extrapolam os limites de uma discussão jurídica, puramente doutrinária, para uma discussão jurídico-política; devo, portanto, utilizar elementos midiáticos para dar conta desses elementos que extrapolam os limites da discussão puramente legal, doutrinária.

O jornal Diário Carioca pode ser considerado o mais próximo, alinhado ao Governo Vargas (SILVA NETO, 2006). Cerca de 3 meses $^{22}$ antes da promulgação da lei $\mathrm{n}^{\circ} 38 / 1935$, este Jornal começou a publicar uma série de editoriais e matérias de capa defendendo determinada concepção de Segurança Nacional. No dia 22 de janeiro, a publicação trata em seu editorial do projeto de lei que transitava na câmara com o título “A Segurança do Estado" (Idem, p. 59). Poucos dias depois (26), o mesmo jornal publica uma chamada na capa. Nesta publicação informa que “A situação política. Deverá ser apresentada hoje, na Câmara, a futura Lei de Segurança Nacional. Os deputados das grandes e pequenas Bancadas assinaram o projeto. Os extremistas já começaram a espernear”. (Diário Carioca, 26.01.1935, $1^{\text {a }}$ página). Ou seja, esta importante publicação diária, além de tratar a segurança nacional como sinônimo de "Segurança do Estado",

\footnotetext{
${ }^{21}$ Entendo "Segurança do Estado" como um conceito que transforma em criminoso o indivíduo ou grupo de indivíduos que coloquem em risco a elite política que ocupa os cargos de mando no Estado; este risco é medido pela própria elite política; não atoa, o Tribunal de Segurança Nacional julgou em sua maioria indivíduos que defendiam uma ruptura com a modernidade liberal, isto é, Integralistas e comunistas. Para mais informações ver COMBLIN, 1978.

${ }^{22}$ A lei que ficou conhecida como Lei de Segurança Nacional de 1935 foi promulgada no dia 4 de abril de 1935.

CSOnline - Revista Eletrônica de Ciências Sociais, Juiz de Fora, n. 25 (2017), pp. 1-296.
} 
qualifica a minoria parlamentar ${ }^{23}$ que votou contra o projeto como "extremista" e contrário aos interesses nacionais.

Contudo, apesar da tentativa do Diário Carioca de tratar a crítica ao projeto como uma atitude excepcional de uma minoria não fundamentada, já existia por parte desta minoria parlamentar críticas a alguns aspectos inconstitucionais da legislação prósegurança nacional. Essas críticas mostram como a defesa de determinado ponto não era "por conveniência" momentânea, mas sim, fruto de um importante ponto para a segurança jurídica do país.

João Mangabeira, por exemplo, defendia, durante a constituinte de 1934, que não fosse incluído, no anteprojeto, a impossibilidade dos Estados e da União prescreverem leis retroativas. O princípio da irretroatividade deveria ser aplicado apenas para as leis penais, "desde que a lei anterior não se apresentasse mais favorável ao acusado de um delito" (TOURINHO, 1980, p. 13). Isto é, antes da emergência das discussões em torno da segurança nacional no âmbito da Câmara dos Deputados, João Mangabeira já possuía uma posição contrária à direção que a legislação de Segurança nacional tomaria. Segundo Campos (1982), a legislação de Segurança Nacional caminhou em direção a dificultar cada vez mais o direito de defesa, o que pode ser percebido pela análise das Leis $\mathrm{n}^{\circ}$ 38/1935 e 136/1935 e dos Decretos-Lei n431/1938 e n4766/1942.

Desde o início do processo de recrudescimento do regime, Mangabeira sempre se mostrou contrário, votou contra o Estado de sítio que Vargas pedira por conta da revolta comunista de 1935 (nesta revolta, por sinal, seu filho foi preso. Acusado de participação). Fundou junto com Abel Chermont o "grupo parlamentar pró-liberdades populares”, grupo que fazia oposição à AIB e era contra a aprovação de quaisquer mecanismos que pudesse dificultar a defesa e aumentar a pena para os integrantes da revolta de 1935. Como já dissemos, foi um grande crítico da retroatividade penal ${ }^{24}$. Então, podemos tomar que, tanto para Mangabeira quanto os outros integrantes da minoria parlamentar, o léxico da Segurança Nacional vinha acompanhado de um aparato judicial que era extremamente pernicioso para a nação.

A "maioria" parlamentar também se organizara. O Deputado José Eduardo Macedo Soares (PPR/RJ) argumentava que o projeto de lei tratava apenas de regulamentar um dispositivo da Constituição, o número 9 do artigo 113:

\footnotetext{
${ }^{23}$ O projeto de lei foi aprovado no congresso por 111 votos a 17, boa parte desses 17 parlamentares fazia parte do "grupo parlamentar pró-liberdades populares". (MOURELLE, 2015).

${ }^{24}$ Ver MOREIRA. Regina da Luz. MANGABEIRA, João. Dicionário Histórico-Biográfico Brasileiro. Disponível em: http://cpdoc.fgv.br/acervo/dhbb. Acesso em: 31 out. 2016.

CSOnline - Revista Eletrônica de Ciências Sociais, Juiz de Fora, n. 25 (2017), pp. 1-296.
} 
“Art 113 - A Constituição assegura a brasileiros e a estrangeiros residentes no País a inviolabilidade dos direitos concernentes à liberdade, à subsistência, à segurança individual e à propriedade, nos termos seguintes: 9) Em qualquer assunto é livre a manifestação do pensamento, sem dependência de censura, salvo quanto a espetáculos e diversões públicas, respondendo cada um pelos abusos que cometer, nos casos e pela forma que a lei determinar. Não é permitido anonimato. É segurado o direito de resposta. A publicação de livros e periódicos independe de licença do Poder Público. Não será, porém, tolerada propaganda, de guerra ou de processos violentos, para subverter a ordem política ou social." 25

Ao final da manifestação do deputado, é dito que a lei "defende e assegura a ordem e a tranquilidade do País" (Diário Carioca, 26.01.1935, 1ª página). Este deputado, que representa a maioria parlamentar, começa a delinear os contornos da "visão oficial" do que seria a Segurança Nacional, podemos perceber então que: 1) a Segurança Nacional era entendida como certa "moral" difusa que zelava pela "ordem" política e social, esta ordem estaria identificada muitas vezes com a manutenção de certos grupos sociais no poder; 2) ao contrário do que defendiam seus detratores, o projeto era apresentado como uma forma de "regulamentar" um dispositivo da constituição.

A partir de 21 de março de 1936, o estado de sítio, ao qual Mangabeira e seus correligionários já tinham se contraposto, foi transformado em estado de guerra. Esta manobra política permitia que os poderes do chefe de governo fossem ampliados. ${ }^{26}$ Neste dia, o deputado João Mangabeira e outros quatro parlamentares, incluindo o Senador Abel Chermont, foram presos acusados "de atuarem como um 'comitê parlamentar a serviço do líder comunista Luís Carlos Prestes', ajudando a reorganizar atividades subversivas."27 Ou seja, a contraposição a determinada concepção de Segurança Nacional foi destruída não pela fraqueza argumentativa, mas sim, pela ação do braço repressivo do Estado. Este processo, certamente, contribuiu para o que Celina (2006) chamou de forma autoritária que a questão da Segurança Nacional e da justiça militar permearam o país.

Em Setembro de 1936, ao perceber que seria julgada por um tribunal de exceção, Mangabeira impetrou um Habeas Corpus preventivo no $\mathrm{STF}^{28}$ :

\footnotetext{
25 <http://www.planalto.gov.br/ccivil_03/Constituicao/Constituicao34.htm> Acessado em: 1 nov. 2016.

${ }^{26}$ Ver FRAGOSO, Heleno. LEI DE SEGURANÇA NACIONAL. Dicionário Histórico-Biográfico Brasileiro. Disponível em: http://cpdoc.fgv.br/acervo/dhbb. Acesso em: 15 nov. 2016.

${ }^{27}$ Ver MOREIRA. Regina da Luz. MANGABEIRA, João. Dicionário Histórico-Biográfico Brasileiro. Disponível em: http://cpdoc.fgv.br/acervo/dhbb. Acesso em: 31 out. 2016.

${ }^{28}$ Este posteriormente seria negado pelo Relator.

CSOnline - Revista Eletrônica de Ciências Sociais, Juiz de Fora, n. 25 (2017), pp. 1-296.
} 
"Notai bem, senhores ministros. Nem os tribunais de salvação pública da Revolução Francesa; nem os russos em meio à guerra civil; nem os do hitlerismo, no primeiro movimento de sua explosão, e ainda inseguros no poder, como no caso do incêndio do Reichstag; nem agora na Espanha, as cortes marciais, de ambos os lados, condenados à morte os seus adversários; nem em plena zona de guerra, de 1914 a 1918, os conselhos militares, julgando espiões, covardes, desertores, ou traidores; em nenhum desses casos, nenhum país ousou inverter a regra suprema do processo e atribuir preliminarmente ao acusado a prova de não haver praticado o crime. Reservara o destino ao Brasil a torpeza dessa iniciativa abominável. Como nos julgará a História, se a Justiça regular não opuser o seu 'non possumus' ao delírio furioso dessa loucura? Porque é tão sagrada essa tradição, é tão fundamental à Justiça esse princípio, que no primeiro dos livros bíblicos o próprio Deus Onipotente e Sabedor de todas as coisas não ousou condenar Caim, manchado no sangue do irmão, sem primeiro interrogá-lo - 'quid fecisti'? Que fizeste? Ele próprio não dera, desde logo, por provado o fratricídio que sua onividência presenciara. Ele - o 'judex justus'. Os juízes de 'consciência livre' procederão, porém, de outra maneira. É esse princípio que remonta às mais longínquas tradições da história e se embebe nas origens de sua ignorância e o sorriso da sua inconsciência. (...) Mas, esses julgamentos de 'consciência livre' por juízes nomeados livremente pelo Poder Executivo e com a faculdade de aplicarem, ao cabo de um processo clandestino, penas retroativas, contra acusados indefesos, hão de ficar na história da civilização humana, como símbolos eternos de ignomínia e desonra. E é sob a ameaça iminente dessa coação que o impetrante recorre a essa Egrégia Corte e lhe impetra este 'habeas corpus', para que não seja processado pelo monstruoso Tribunal de Segurança, mas por um dos juízes federais deste Distrito, como lhe assegura o artigo 81 da Constituição" 29.

Neste Habeas Corpus, João Mangabeira estabelece a relação entre Segurança Nacional e a fabricação de um tipo social desprovido de direitos, além do aparato estatal repressivo e autoritário que já fazia parte do discurso da segurança nacional. O autor desta peça jurídica inicia mostrando que os mais diversos tribunais de exceção ao redor do mundo não possuem mecanismos semelhantes aos que foram empregados no país, através do conceito de segurança nacional. Com o decorrer do texto, mostra como o sujeito que aflige certa moral difusa de garantia da ordem social e política fica desprovido de diversas garantias como o princípio "In dubio pro reo"; como os juízes, durante o processo de

\footnotetext{
${ }^{29}$ Retirado do correio eletrônico <http://www.oabsp.org.br/sobre-oabsp/grandes-causas/a-longa-lutacontra-a-ditadura> Acessado em 16 nov. 2016.

CSOnline - Revista Eletrônica de Ciências Sociais, Juiz de Fora, n. 25 (2017), pp. 1-296.
} 
análise das provas, poderia decidir por "livre convicção" "30; como a retroatividade penal; e a não observância do Artigo $\mathrm{n}^{\circ} 81$ da Constituição de 1934, que estabelecia a competência dos Juízes federais ${ }^{31}$.

\section{Atuação de um ministro: os limites dos Habeas Corpus nos casos de Segurança Nacional}

A discussão das fontes do Ministro Carlos Maximiliano, ao contrário da subseção anterior, torna-se mais circunscrita à esfera jurídica. Isto ocorre porque o Ministro Carlos Maximiliano manifestava-se através de sua atuação no âmbito do STF e não de forma difusa em manifestações parlamentares e Habeas Corpus.

Atuou ininterruptamente como ministro em duas realidades constitucionais diferentes. Enquanto a Constituição de 1934 aumentava a autonomia do STF frente ao poder executivo, a Constituição de 1937 foi uma afronta ao órgão de cúpula do judiciário, abrindo precedentes para o chefe do executivo demitir ministros e cortar vencimentos ${ }^{32}$.

Analisaremos três votos proferidos pelo Ministro, todos referentes à Habeas Corpus votados nos primeiros anos de análise, até 1938, para mostrar como o órgão de cúpula do judiciário começou a criar sua jurisprudência sobre questões relacionadas à Segurança Nacional. O primeiro refere-se ao Recurso Ordinário de Habeas Corpus (RHC) $n^{\circ}$ 26.287/BA, julgado em novembro de 1936, este foi o primeiro Habeas Corpus debatido em decorrência de uma prisão utilizando a "força de lei" da segurança nacional. O segundo refere-se ao Habeas Corpus (HC) n 26.556/DF, julgado em outubro de 1937 ,

\footnotetext{
${ }^{30}$ O princípio de julgamento por "livre conviç̧ão" está descrito na mesma lei que institui o Tribunal de Segurança Nacional: Lei no 244/1936. Sobre o princípio da "livre conviç̧ão": Ver NUNES, 2013.

${ }^{31}$ CF 1934 Art. 81 - Aos Juízes federais compete processar e julgar, em primeira instância: a) as causas em que a União for interessada como autora ou ré, assistente ou oponente; b) os pleitos em que alguma das partes fundar a ação ou a defesa, direta e exclusivamente em dispositivo da Constituição; c) as causas fundadas em concessão federal ou em contrato celebrado com a União; d) as questões entre um Estado e habitantes de outro, ou domiciliados em país estrangeiro, ou contra autoridade administrativa federal, quando fundadas em lesão de direito individual, por ato ou decisão da mesma autoridade; e) as causas entre Estado estrangeiro e pessoa domiciliada no Brasil; f) as causas movidas com fundamento em contrato ou tratado do Brasil com outras nações; g) as questões de Direito marítimo e navegação no oceano ou nos rios e lagos do País, e de navegação aérea; $h$ ) as questões de Direito Internacional Privado ou Penal; i) os crimes políticos e os praticados em prejuízo de serviço ou interesses da União, ressalvada a competência da Justiça Eleitoral ou Militar; j) os habeas corpus, quando se tratar de crime de competência da Justiça federal, ou quando a coação provier de autoridades federais, não subordinadas imediatamente à Corte Suprema; k) os mandados de segurança contra atos de autoridades federais, excetuado o caso do art. 76, 1, letra i; I) os crimes praticados contra a ordem social, inclusive o de regresso ao Brasil de estrangeiro expulso. Parágrafo único - $O$ disposto no presente artigo, letra a , não exclui a competência da Justiça local nos processos de falência e outros em que a Fazenda Nacional, embora interessada, não intervenha como autora, ré, assistente ou oponente.

${ }^{32}$ Sobre as diferentes realidades que o Supremo Tribunal Federal passou durante o nosso período Republicano: Ver ALVES JUNIOR, 2004.

CSOnline - Revista Eletrônica de Ciências Sociais, Juiz de Fora, n. 25 (2017), pp. 1-296.
} 
nele o impetrante, Willy Baungarten, era acusado de se envolver "em atividades perigosas à ordem pública e nocivas à segurança nacional" (GODOY, 2010, p. 78); em seu voto, Carlos Maximiliano discorda do relator, dando outro olhar sobre a matéria. O terceiro refere-se ao Habeas Corpus $\mathrm{n}^{\circ}$ 26.836/PE, julgado em agosto de 1938, e trata basicamente dos contornos da Lei de Segurança Nacional.

A primeira peça, como já foi mencionada refere-se ao $\mathrm{RHC} \mathrm{n}^{\circ} 26.287 / \mathrm{BA}$, e fazse importante por ser o desfecho da primeira votação sob a égide da legislação da Segurança Nacional no que tange o caso concreto do direito:

"VOTO O Sr. Ministro Carlos Maximiliano: Senhor Presidente, pela sistemática do nosso direito, o juiz competente para tomar conhecimento de um fato delituoso, ao ponto de julgar um fato concernente a esse delito ou ao delito em si, é também o competente para conhecer do habeas corpus requerido por pessoas presas ou ameaçadas de prisão, como incursas na mesma disposição legal. De sorte que, se há um tribunal especial para conhecer de determinada figura delituosa, esse tribunal será também o competente, em primeira instância, para conhecer do habeas corpus. Por conseguinte, se se trata, como o reconhecem os impetrantes e afirma o juiz federal, de um delito de esfera de um tribunal especial, organizado há pouco tempo, a esse tribunal caberia conhecer do habeas corpus. Não me impressiona o hábil argumento de que o aludido tribunal será sempre um tribunal a quo. Sê-lo-ia se a prisão fosse determinada por ele. E, então, o caso de prisão preventiva ou de prisão em virtude de pronúncia ou de sentença. Mas, desde que a prisão não foi determinada pelo tribunal em questão e sim por uma autoridade policial, seria um tribunal ad quem. Surge aí uma dificuldade: a Constituição manda que, toda vez que um tribunal superior verificar que não é o competente para conhecer da espécie, deve remeter os autos a magistrado que lhe pareça competente. Nesse ponto, não opinaria pela remessa do processo, porque essa ordem importaria, de minha parte, resolver, preliminarmente, uma questão de competência, que não cabe. Só devo conhecer ou não do despacho, sobretudo porque o caso está colocado num terreno em que o Judiciário não pode intervir. No estado de sítio, se a autoridade informar falsamente, ficará, mais tarde, sujeita a um processo de responsabilidade; durante o estado de guerra, desde que informe ao Poder Judiciário que o indivíduo está preso ou ameaçado de prisão, tolhido em sua liberdade, por motivo de segurança nacional, não se executa in limine o pedido. Se assim é no estado de guerra, com maioria de razão no estado de sítio, que não é mais que um estado de sítio terrivelmente agravado, onde diminuem ao invés de aumentarem as garantias constitucionais. Por esses motivos, limito-me a confirmar o despacho do juiz,

CSOnline - Revista Eletrônica de Ciências Sociais, Juiz de Fora, n. 25 (2017), pp. 1-296. 
isto é, nego provimento ao recurso. E não tomo conhecimento originário do pedido por causa do estado de guerra." (GODOY, 2010, p. 78-9).

De acordo com o voto de Maximiliano, no Recurso ordinário ao Habeas Corpus, proferido em novembro de 1936, podemos observar uma crítica ao estado de guerra que, segundo ele, retira direitos ao invés de garanti-los. Numa tentativa de protesto, com relação a esse estado de guerra, Maximiliano prefere não tomar conhecimento da matéria porque este interferiria na ordem jurídica causando um conflito de competência que ele absteve-se de resolver. Contudo, alguns aspectos devem ser destacados: 1) por trás da retórica de "não tomar conhecimento", o ministro acaba por concordar com o Juiz de primeira instância e negar o Habeas Corpus, contribuindo para que o tribunal de exceção continuasse seus trabalhos, ou seja, o estado de guerra, segundo Maximiliano, criava um ordenamento jurídico que não era possível definir qual órgão era competente para julgar os recursos, mas nesse mesmo ordenamento o funcionamento da TSN era tolerado via omissão; 2) se não fosse o estado de guerra, o ministro deixa claro que a competência para julgar a matéria seria do próprio tribunal, isto é, por meio do julgamento de uma pauta referente à segurança nacional, o magistrado começa a delinear a estrutura política vindoura, em que o Tribunal de Segurança Nacional seria responsável pela primeira e segunda instância de julgamentos (CAMPOS, 1982).

A segunda peça refere-se ao $\mathrm{HC} \mathrm{n}^{\circ} 26.556 / \mathrm{DF}$, julgado em outubro de 1937 , nele um estrangeiro, Willy Baungarten, era acusado de ser nocivo à segurança nacional e se envolver em atividades perigosas (duas tipificações penais extremamente subjetivas); e Carlos Maximiliano discorda do relator:

"VOTO O Sr. Ministro Carlos Maximiliano: Senhor Presidente, segundo as informações que acabo de ouvir, prestadas pela Chefia da Polícia do Distrito Federal e lidas pelo Sr. Ministro Relator, parece-me que se trata de um caso vulgar de estrangeiro que, tendo vindo ao Brasil com passaporte de turista, aqui se encontra por prazo excedente aos três meses de permanência, a que dá direito essa espécie de passaporte. Intimado a deixar o país, declarou às autoridades que não tem dinheiro para comprar passagem de volta; deve, por isso, ser compelido a sair. Não se trata, porém, de indivíduo prejudicial à ordem pública. Não se encontra, nas informações da Polícia, qualquer referência a esse respeito. É caso semelhante ao dessa moça alemã, de que tive notícia pelos jornais europeus, coagida pelas nossas autoridades a deixar o país por ter excedido o prazo que lhe facultava o passaporte. Acho que o indivíduo em questão pode ser obrigado a embarcar, a deixar o país, porque excedeu o prazo durante o qual the era permitido aqui permanecer. Não me parece, porém, que deva ficar preso, uma vez que não se trata de elemento prejudicial à ordem

CSOnline - Revista Eletrônica de Ciências Sociais, Juiz de Fora, n. 25 (2017), pp. 1-296. 
pública. Nestas condições, concedo o habeas corpus, para que seja posto em liberdade sem prejuízo da expulsão." (GODOY, 2010, p. 78).

O Ministro Relator negou o pedido de Habeas Corpus, aderindo à jurisprudência da Corte nesses casos. Carlos Maximiliano, ao seu turno, observou que não havia sido praticada nenhuma atividade nociva, e então, declarou que o impetrante poderia sair do país, uma vez que, seu tempo de permanência já havia expirado. A respeito desse voto, podemos destacar que no trecho: "Não se trata, porém, de indivíduo prejudicial à ordem pública. Não se encontra, nas informações da Polícia, qualquer referência a esse respeito.” (l. 7-9), existe por trás da defesa, uma aceitação da ideia de que existe um tipo social, um tipo de indivíduo que seria prejudicial à ordem, então, os próprios operadores do direito contribuíram para delinear esse "tipo". Outro ponto relevante a ser destacado é que se a "maioria parlamentar" defendia o ideal de ordem de acordo com uma "moral", os “aplicadores da lei" se pautavam na subjetividade dos tipos penais e em certos mecanismos de exceção, como um estado de guerra que retirava a certeza sobre a competência dos órgãos dentro do judiciário, mas permitia o funcionamento de um tribunal especial.

A terceira trata do $\mathrm{HC} \mathrm{n}^{\circ}$ 26.836/PE, julgado no ano de 1938, tratando, exatamente, dos contornos jurídicos da lei de Segurança Nacional. Este já havia sofrido duas modificações: uma pela lei n 136/1935 e outra pelo Decreto-Lei n431/1938. Segue o voto do Ministro:

"O Sr. Ministro Carlos Maximiliano: Senhor Presidente, estou de acordo com o peticionário e o seu ilustre advogado em que a nova lei de segurança constitui, realmente, um sistema integral, de maneira que todos os dispositivos da anterior, que não estejam explicitamente restabelecidos, se consideram revogados. Este crime, porém, como bem ficou demonstrado, é o mesmo previsto no art. 112 do Código Penal, que diz: Usar de violência ou ameaças, contra os agentes do poder executivo federal, ou dos Estados, para os forçar a praticar ou deixar de praticar um ato oficial. Este dispositivo foi modificado pela Lei 38, art. $3^{\circ}$ : Opor-se alguém, por meio de ameaça ou violência, ao livre e legítimo exercício de funções de qualquer agente de poder político da União. E a nova lei: Usar de ameaça ou violência para forçá-lo (ao funcionário público) a praticar ou deixar de praticar qualquer ato do ofício, ou obrigar a exercê-lo em determinado sentido. Está-se vendo que é a mesma disposição, mudando apenas a redação. Como, afinal, a pena foi discriminada, aplica-se o art. $3^{\circ}$ do Código Penal, que, como bem concluiu o Sr. Ministro Relator, não foi revogado pela Constituição. Não foi isto o que visou a nossa Carta Magna; o que ela teve em vista foi dar garantias e não tirá-las. Houve, apenas, uma

CSOnline - Revista Eletrônica de Ciências Sociais, Juiz de Fora, n. 25 (2017), pp. 1-296. 
redação apressada, que não previu claramente a hipótese, mas não revogou expressamente o dispositivo do Código Penal. Como bem disse o Sr. Ministro Carvalho Mourão, trata-se de princípio seguido universalmente e que somente por dispositivo claro de lei podia ser considerado revogado. Por esses motivos, estou de acordo com o Sr. Ministro Relator. Se a pena foi diminuída, concedo a ordem, porque o paciente já cumpriu a pena a que devia ter sido condenado." (GODOY, 2010, 92-3).

Comumente, o Supremo Tribunal Federal julgava improcedente os pedidos de habeas corpus durante este período. Neste caso, muito graças a essa desambiguação, o entendimento da corte foi diferente. Contudo, a interpretação da peça abre margem para a discricionariedade, isto é, alegando que a lei teve uma redação apressada o intérprete da Constituição justifica a escolha por determinada interpretação.

Portanto, podemos perceber que a interpretação do direito por parte de membros do STF também ajudou a criar determinado entendimento de segurança nacional e a criar um tipo social que deveria ser julgado de acordo com esses mecanismos de exceção. Isto fica claro ao percebermos que Carlos Maximiliano, no primeiro habeas corpus, toma o estado de guerra como uma justificativa para que o tribunal continue funcionando, mesmo que por omissão; no segundo, mesmo concedendo o habeas corpus, justifica a existência do tribunal baseado na existência de um "indivíduo prejudicial à ordem pública"; no terceiro, por fim, mostra que os juízes poderiam interpretar a lei por meio do casuísmo, em que ora vale o texto constitucional e ora vale a modificação feita na lei $38^{33}$.

\section{Acadêmico e o Magistrado: Teoria e prática confrontam Hungria}

Nessa parte do texto, o fio condutor da análise será a produção jurídica de Nelson Hungria. Observando tanto a atividade acadêmica quanto outras atividades jurídicas, uma vez que, o magistrado teve participação ativa na elaboração do Código Penal, do Código de Processo Penal, da Lei das Contravenções Penais e da Lei de Economia Popular, as duas primeiras desenvolvidas em pleno Estado Novo. (FUCK, 2012, p. 21).

Em primeiro lugar, analisaremos de onde parte a ambiguidade que marca a atuação do Magistrado Nelson Hungria. De um lado, critica a concepção própria do direito penal nazista, baseada na Escola de Kiel. De outro, aceita que o arcabouço jurídico da segurança nacional tenha espaço no rol das justiças especiais. Em um artigo intitulado A Evolução do Direito Penal brasileiro, Hungria afirma que:

\footnotetext{
${ }^{33}$ A lei n³8/1935. Conhecida como lei de Segurança Nacional de 1935. CSOnline - Revista Eletrônica de Ciências Sociais, Juiz de Fora, n. 25 (2017), pp. 1-296.
} 
“(...) em toda a América Latina, foi o Brasil o primeiro país em que ressoou uma voz, desautorizada, mas convencida, contra o direito penal autoritário da Alemanha nacional-socialista, que já estava aliciando espíritos aquém Atlântico. Em conferências por mim proferidas em 1936 e 1937 (...) no discurso que inaugurou o último Congresso Latino-Americano de criminologia, procurei demonstrar que a denominada 'Escola de Kiel' não assentava sobre fundamentos sérios, mas apenas servia ao ferrenho antiliberalismo nazista”. (DAL RI Jr, 2012 apud HUNGRIA, 1943).

Neste artigo, Hungria mostra que determinada visão do direito penal brasileiro é debitária da "Escola de Kiel”, no trecho destacado, podemos observar que esta concepção do "direito penal autoritário" não é uma particularidade brasileira, estando presente "em toda a América Latina", assim como afirma Comblin (1978). Além de não ser uma concepção jurídica circunscrita ao território nacional, Hungria destaca que os fundamentos da escola não se justificam per se. Justificam-se apenas pelo seu uso político, seu traço repressivo.

Contudo, a ambiguidade presente na atuação de Nelson Hungria começa a transparecer ao observarmos um trecho do Novo Código Penal" ${ }^{34}$ " $\mathrm{Na}$ atual fase de não conformismo, ou de espírito de rebeldia contra as instituições políticas ou sociais, a defesa destas, sob o ponto de vista jurídico-penal, reclama uma legislação especialíssima, de feitio drástico, desafeiçoada aos critérios tradicionais do direito repressivo" (HUNGRIA, 1941, p. 275). Isto é, apesar de argumentar que a concepção penal autoritária era uma ficção e que a sua existência se justifica apenas pela utilização política; Hungria argumenta que, de acordo com as circunstâncias, essa concepção errônea poderia encontrar um local em alguma "legislação especialíssima".

Em segundo lugar, faz-se necessário analisar um ponto peculiar da jurisprudência do Desembargador do Distrito Federal, esse entendimento se arrastaria até 1953, como ministro do STF. Apesar da atuação como ministro não entrar na análise por exceder o recorte cronológico proposto, vale como menção.

$\mathrm{O}$ aspecto mencionado é que Hungria afirmou em diversas decisões que a Lei de Segurança Nacional de 1935, com as suas posteriores modificações ${ }^{35}$, era condizente com a CF/1946, reforçando a ambiguidade mencionada nos parágrafos anteriores. Chegando a argumentar que “a incriminação da difusão ou perigo de difusão de processos

\footnotetext{
${ }^{34}$ Nelson Hungria assina, sozinho, esta obra de comentários sobre o Código Penal; há, portanto, fortes indícios de que ele seja o autor desta interpretação.

${ }^{35}$ A lei $n^{\circ} 38 / 1935$, que ficou conhecida como lei de segurança nacional, sofreu três modificações, através da lei $n^{\circ} 136 / 1935$ e dos Decretos-Lei ${ }^{\circ} 431 / 1938$ e n4766/1942.

CSOnline - Revista Eletrônica de Ciências Sociais, Juiz de Fora, n. 25 (2017), pp. 1-296.
} 
subversivos da nossa ordem política, no meu entender (...) não colide com a constituição, não ofende nenhum de seus preceitos" (FUCK, 2012, p. 37). Sua concepção jurídica, não via nenhum empecilho entre a vigência da Lei de Segurança Nacional e a Constituição democrática de 1946. Decisões que corroboram essa visão foram procedidas na apelação criminal 1.479/DF, no Acórdão 1452/SP de 1951 e no HC 32.618/SP de 1953. Chegando a argumentar em alguns casos que a lei de segurança nacional, encontrava sustentação constitucional no capítulo "direitos e garantias individuais". $\mathrm{Na}$ apelação criminal 1479/DF, ele argumenta que se houver "dolo", intenção, o dispositivo legal oriundo da lei $n^{\circ}$ 38/1935 têm espaço no ordenamento jurídico. Segue a peça jurídica:

"APELAÇÃO CRIMINAL 1.479 - DF VOTO O Sr. Ministro Nelson Hungria: Senhor Presidente, sempre entendi que, para existência do crime previsto no inciso 18 do art. $3^{\circ}$ da Lei 431, de 1938, é indispensável que seja reconhecido o seu dolo específico, que é o fim de atentar contra a segurança nacional ou a ordem político-social. Este entendimento, aliás, foi o que prevaleceu no extinto Tribunal de Segurança. (...)" (FUCK, 2012, p. 216$)^{36}$.

Ou seja, tanto na década de 1930 quanto nas décadas seguintes, houve um "esforço" por parte dos intérpretes da lei em encontrar um espaço no ordenamento jurídico para a legislação sobre crimes políticos. Durante o período em que a atuação de Hungria como Desembargador foi consolidada, a evocação da segurança nacional deixa de ser uma "moral" difusa defendida pelos defensores da "ideologia" do Estado ${ }^{37}$ ou um corpo totalmente estranho ao mundo jurídico que se apropria das subjetividades dos tipos penais para criar um sujeito desprovido de direitos, como em alguns votos proferidos pelo ministro Carlos Maximiliano; para tornar-se um mecanismo que seria, segundo Hungria, não só compatível, mas sustentado pelo texto constitucional.

\section{Conclusão: amarrando os dados}

Tenho a consciência de que os atores trabalhados não findam a questão da disputa em torno do conceito de segurança nacional, mas mostram como os atores foram produto e produtores das transformações que o conceito de segurança nacional passou no período observado. Mostrando, principalmente, como alguns juristas, exercendo as mais variadas funções, enfrentaram a questão da segurança nacional ou como, mesmo a contragosto,

\footnotetext{
${ }^{36}$ Esta decisão foi proferida quando Hungria era ministro do STF. Apesar de ter extrapolado o marco final do recorte cronológico, argumento aqui que esta concepção foi germinada desde sua atuação como Desembargador, tomando contornos melhor delineados durante sua atuação posterior.

${ }^{37}$ Os defensores da "ideologia" do Estado são, como podemos perceber na seção dedicada a João Mangabeira, parte da imprensa e a maioria parlamentar.

CSOnline - Revista Eletrônica de Ciências Sociais, Juiz de Fora, n. 25 (2017), pp. 1-296.
} 
criaram mecanismos para que determinada concepção autoritária do conceito encontrasse um locus no ordenamento jurídico nacional.

No livro Crítica e Crise, Koselleck (1999) examina a função política que o pensamento e as aspirações da burguesia tiveram no âmbito do Estado absolutista, isto é, como determinados conceitos justificam/proporcionam certos movimentos; mudanças políticas. A partir disso, Koselleck estuda de forma sincrônica o desenvolvimento de um tipo de filosofia que tem como sujeito a humanidade inteira - a filosofia da história - e a estrutura política do Estado absolutista. Este trabalho, tratando-se de um esforço muito menor, pretendeu mostrar como a significado político do conceito alterou-se durante os anos de recrudescimento do regime Varguista.

A Constituição de $1934^{38}$, possuía um título dedicado à Segurança Nacional. Este, contudo, distanciava muito da concepção de Segurança Nacional que foi construída nos anos subsequentes. O Título IV, Da Segurança Nacional dispõe de nove artigos: os artigos 159 e 160 definem os participantes e as incumbências do Conselho Superior de Segurança Nacional; o artigo 161 define implicações do Estado de Guerra; do artigo 162 ao 165 são tratados de temas como o alistamento e a hierarquia das Forças Armadas; o artigo 166 implementa o monopólio do Conselho Superior de Segurança Nacional nas decisões em diversas matérias em regiões de fronteiras nacionais; e, por fim, o artigo 167 que tratam as polícias militares como forças de reserva para as Forças Armadas. Ou seja, o conceito de Segurança nacional na $\mathrm{CF} / 34$ não possui a carga autoritária que o conceito viria assumir posteriormente; abordando basicamente de questões em regiões de fronteiras e questões referentes as competências internas das Forças Armadas.

O caminho trilhado por esse trabalho foi mostrar o percurso que o conceito seguiu desde a concepção descrita no texto constitucional de 1934 até a jurisprudência de um alto magistrado federal ao final do período analisado. A reação à Revolta Comunista de 1935 criou um alvoroço midiático e em representantes da maioria parlamentar passando a esboçar os primeiros contornos da "visão oficial” sobre Segurança Nacional. Descrevi esse primeiro momento como a criação de uma certa "moral" difusa baseada na ideia de ordem, na ideia de manutenção de certos grupos sociais no poder. A minoria parlamentar, ao seu turno, defendia ainda nesses primeiros anos, que o léxico da Segurança Nacional acompanhado de um aparato judicial que atentava contra os direitos individuais e os dispositivos constitucionais.

\footnotetext{
${ }^{38}$ Ver Constituição de 1934 em: http://www.planalto.gov.br/ccivil 03/Constituicao/Constituicao34.htm. Acessado em 17 nov. 2016.

CSOnline - Revista Eletrônica de Ciências Sociais, Juiz de Fora, n. 25 (2017), pp. 1-296.
} 
Alguns magistrados, durante parte do Estado Novo (1937-8), concediam Habeas Corpus e contrapunham-se à retórica autoritária que começava a se delinear, mas acabavam - propositada ou despropositadamente - por legitimar a sua existência em alguns casos. Vimos como a interpretação do direito por parte de Maximiliano, pautavase na subjetividade dos tipos penais e na aceitação de um "estado de guerra" que, ao mesmo tempo que, gerava incerteza sobre a competência dos órgãos dentro do judiciário, permitia o funcionamento de um tribunal especial. Ajudando a gestar o entendimento sobre segurança nacional em que alguns atores poderiam ser julgados de acordo com esses mecanismos de exceção. Por fim, a interpretação de parte da magistratura brasileira, ao final do período de análise, observados a partir dos escritos de Nelson Hungria já sustenta a legalidades desse ordenamento jurídico que não possuem sustentáculo algum. Essa ordem "nova" teria como função resguardar as normas constitucionais que, em tese, asseguram-lhe a legalidade.

\section{BIBLIOGRAFIA}

AGAMBEN, Giorgio, 1942- Estado de exceção / Giorgio Agamben; tradução de Iraci D. Poleia. - São Paulo: Boitempo, 2004 (Estado de sitio).

ALVES, Maria Helena Moreira. (1987). Estado e oposição no Brasil (1964-1984). Petrópolis: Vozes.

ALVES JÚNIOR, Luís Carlos Martins. O Supremo Tribunal Federal nas constituições brasileiras. Belo Horizonte: Mandamentos, 2004. 472 p.

AVELAR, Mariana; BAMBIRRA, Felipe M. "O Tribunal de Segurança Nacional: Páginas Desbotadas da História". Revista do CAAP, Belo Horizonte, Número Especial: I Jornada de Estudos Jurídicos da UFMG, p. 93 a p. 107, jul./dez. 2010.

BALZ, Christiano. O Tribunal de Segurança Nacional: Aspectos legais e doutrinários de um tribunal da Era Vargas (1936-1945). Dissertação de Mestrado. Dissertação de Mestrado em Direito, UFSC, Florianópolis, 2009.

CAMPOS, Reynaldo Pompeu de. Repressão judicial no Estado Novo: esquerda e direita no banco dos réus. Rio de Janeiro: Achiamé, 1982.

COVELlO, Antonio Augusto de. (1935) A lei de segurança: trabalhos parlamentares. São Paulo: Imprensa Gráfica, Revista dos Tribunais. 
COMBLIN, Joseph. A ideologia da segurança nacional: o poder militar na América Latina. RJ: Civilização Brasileira, 1978.

DA ROS, Luciano. Juízes Profissionais? Padrões de carreira dos integrantes das Supremas Cortes de Brasil (1829-2008) e Estados Unidos (1789-2008). Revista de Sociologia e Política (UFPR. Impresso), v. 20, p. 149-169, 2012.

DAL RI Jr, Arno. “O Conceito de Segurança Nacional na Doutrina Jurídica brasileira: Usos e representações do Estado Novo à Ditadura Militar Brasileira (1935-85)". Revista de Direitos fundamentais e democracia, Curitiba, v.14, n 14, p. 525-543, Julho/Dezembro de 2013.

D'ARAUJO, Maria Celina. "O Tribunal de Segurança Nacional e a Justiça Militar", in Militares, democracia e desenvolvimento: Brasil e América do Sul. Rio de Janeiro: Ed. FGV, 2010, pp. 213-223.

D'ARAUJO, Maria Celina. Justiça Militar, segurança nacional e tribunais de exceção. In: $30^{\circ}$. Encontro Anual da ANPOCS, outubro de 2006, 2006, Caxambu. CD. Caxambu, 2006.

FRAGOSO, Heleno. LEI DE SEGURANÇA NACIONAL. Dicionário HistóricoBiográfico Brasileiro. Disponível em: http://cpdoc.fgv.br/acervo/dhbb. Acesso em: 15 nov. 2016.

FRAGOSO, Heleno Cláudio. “Objeto do Crime”. Revista Forense, Julho, 1977.

FUCK, Luciano Felício. Memória jurisprudencial : Ministro Nelson Hungria / Luciano Felício Fuck. -- Brasília : Supremo Tribunal Federal, 2012. 372 p.

GASPARI, Filipe Natal de. A Segurança Nacional na Era Vargas: uma análise da jurisprudência da Corte Suprema (1935-37). São Paulo: 2014. Monografia Sociedade Brasileira de Direito Público.

GODOY, Arnaldo Sampaio de Moraes. Memória jurisprudencial: Ministro Carlos Maximiliano / Arnaldo Sampaio de Moraes Godoy. - Brasília: Supremo Tribunal Federal, 2010. - (Série memória jurisprudencial)

HUNGRIA, Nelson. A Evolução do Direito Penal Brasileiro. Revista Forense, Julho 1943.

HUNGRIA, Nelson. O Nôvo Código Penal. Revista Forense, 1941.

JASMIN, Marcelo Gantus. História dos Conceitos e Teoria Política e Social: Referências Preliminares. Revista Brasileira de Ciências Sociais. Volume 20, n57, Fevereiro/2015. P. 27-38. 
KOSELLECK, Reinhart. Crítica e crise. Tradução: Luciana Villas-Boas Castelo-Branco. Rio de Janeiro: UERJ/Contraponto, 1999, 256 páginas.

KOSELLECK, Reinhart. Futuro passado: Contribuição à Semântica dos tempos históricos. Rio de Janeiro: Contraponto: Ed. PUC-Rio, 2006.

LAMARÃO, Sérgio. GRUPO PARLAMENTAR PRÓ-LIBERDADES POPULARES.

Dicionário Histórico-Biográfico Brasileiro. Disponível em: http://cpdoc.fgv.br/acervo/dhbb. Acesso em: 31 out. 2016

LEMOS, Renato. HUNGRIA, Nelson. Dicionário Histórico-Biográfico Brasileiro. Disponível em: http://cpdoc.fgv.br/acervo/dhbb. Acesso em: 15 jun. 2016.

MESURINI, Maurício da Costa; DIRSCHNABEL, L. . A doutrina da segurança nacional: justificação da ditadura e perseguição do 'inimigo'.. Revista de Direito Univille, v. 2, p. 9-25, 2012.

MOREIRA. Regina da Luz. MANGABEIRA, João. Dicionário Histórico-Biográfico Brasileiro. Disponível em: http://cpdoc.fgv.br/acervo/dhbb. Acesso em: 31 out. 2016. MOREIRA. Regina da Luz. MAXIMILIANO, Carlos. Dicionário Histórico-Biográfico Brasileiro. Disponível em: http://cpdoc.fgv.br/acervo/dhbb. Acesso em: 29 out. 2016. MOURELLE, Thiago Cavaliere. Guerra pelo poder. A Câmara dos Deputados confronta Vargas (1934-35). Programa de pós-graduação em história da Universidade Federal Fluminense, 2015. 218p.

NUNES, Diego. “O Tribunal de Segurança Nacional e o valor da prova testemunhal: o debate sobre o princípio da livre convicção do juiz a partir do julgamento do processo $\mathrm{n}^{\mathrm{o}}$. 1.355." Revista Eletrônica Direito e Política, Programa de Pós-Graduação Stricto Sensu em Ciência Jurídica da UNIVALI, Itajaí, v.8, n.2, 2º quadrimestre de 2013.

NUNES, Diego. O Processo dos crimes políticos durante a era Vargas (1935-1945). Do Direito Italiano ao Direito da Segurança Nacional brasileiro. Florianópolis: Programa de mestrado em Dieito da UFSC, 2010.

OLIVEIRA, Fabiana Luci. Justiça, Profissionalismo e Política - O STF e o controle de constitucionalidade das leis no Brasil. 1. ed. Rio de Janeiro: Editora FGV, 2011. 260p.

RICOUER, Paul. Introdução à Edição Portuguesa de "O Conflito de Interpretações." In: O Conflito de Interpretações: Ensaios de Hermenêutica. Tradução de M. F. Sá Correia. Paris: Editions du seuil, 1978. Pág. 1-8.

SANTOS, André Marenco dos; DA ROS, Luciano . Caminhos que levam à Corte: carreiras e padrões de recrutamento dos ministros dos órgãos de cúpula do Poder 
Judiciário brasileiro (1829-2006). Revista de Sociologia e Política (UFPR. Impresso), v. 16, p. 131-149, 2008.

SEGAL, Jeffrey; SPAETH, Harold. The Supreme Court and the atitudinal model. Cambridge: Cambridge University Press, 1993.

SILVA, Angela Moreira Domingues da. Ditadura militar e justiça castrense no Brasil: espaço de legitimação política e de contradições?. In: I Encontro Nacional da ASSOCIAÇÃO BRASILEIRA DE ESTUDOS DE DEFESA - ABED, 2007, São Carlos - SP. Anais do I Encontro Nacional da ABED, 2007.

SILVA NETO, Casimiro Pedro da Década de 1930 [manuscrito] : os anos de incertezas : a origem da primeira Lei de Segurança Nacional / Casimiro Pedro da Silva Neto. - 2006. 136 f. : il.

SKINNER, Q. Liberdade antes do liberalismo. Tradução de Raul Fiker. São Paulo: Unesp, 1999

TACITO, Caio. A Segurança Nacional no Direito Brasileiro. Revista de Direito Administrativo, v. 69. Ano: 1962.

TOURINHO, Arx. In: Em torno das ideias constitucionalistas de João Mangabeira. REVISTA DE INFORMAÇÃO LEGISLATIVA. Volume 17, n. 66 (abr./jun. 1980).

VIANNA, Luiz Werneck. Os intelectuais da tradição e a modernidade: os juristaspolíticos da OAB. In: VIANNA, Luiz Werneck. Travessia: da Abertura à Constituinte. Rio de Janeiro: Livraria Taurus Editora, 1986

ZAFFARONI, E. Raúl; BATISTA, Nilo et alii. Direito Penal Brasileiro. Volume I. Rio de Janeiro: Revan, 2008. 